\title{
Using EU-SILC to design and evaluate policies against child poverty in Spain
}

\author{
Alejandro Arias ${ }^{1}$, Albert F. Arcarons ${ }^{1}$, Amparo González-Ferrer ${ }^{1}$ \\ ${ }^{1}$ Office of the High Commissioner against Child Poverty
}

\begin{abstract}
EU-SILC is an essential tool for research on social policy. This article compiles, on one hand, the applications of this survey by the Office of the High Commissioner against Child Poverty in Spain. This Office used the Spanish version of the survey on fields such as the design of a minimum income scheme, the evaluation of energy poverty from a child perspective, the changing dynamics of poverty according to country of origin, or the impact of housing costs on poverty. On the other hand, the article also proposes some recommendations for possible improvements of the survey, such as the introduction of labour market trajectories or information on daily living expenses, for instance schooling costs.
\end{abstract}

Keywords: EU-SILC, Spain, poverty, child poverty, public policy, evaluation.

MSC: 62P20, 62P25, 91B82

\section{Introduction}

Eurostat has periodically published information on at-risk of poverty rates in the EU since 1995. These figures have systematically ranked Spain in the worst positions within the EU, especially when focusing on child poverty. According to the most recent data, in 2018, 26.8 per cent of children in Spain lived in households with income below the poverty line $(60 \%$ of the median equivalent income). ${ }^{1}$ Importantly, such a bad position was not a direct consequence of the crisis (in 2008, child poverty affected 27.3 per cent of children), although it obviously contributed to worsen it. Moreover, child poverty is particularly persistent in Spain: in 2018, approximately 75 per cent of children at risk of poverty had also been in poverty in at least two of the three previous years. In other words, child poverty in Spain is particularly high, much more than expected for a country with its level of

\footnotetext{
${ }^{1}$ Equivalised disposable income is the total income of a household that is available for spending or saving, divided by the number of household members converted into equivalised adults. Household members are equivalised or made equivalent by the following so-called modified OECD equivalence scale: the first household member aged 14 years or more counts as 1 person; each other household member aged 14 years or more counts as 0.5 person; each household member aged 13 years or less counts as 0.3 person
} 
economic and social development. Besides, poverty seems to be a persistent experience for children, which threatens to leave indelible imprints on their adulthood.

Aware of the previous figures and the enormous challenge ahead, the last Socialist government decided to create the High Commissioner against Child Poverty (ACPI, its acronym in Spanish) in June 2018, to put child poverty at the centre of the political agenda. In other words, the very creation of the High Commissioner was partly due to EU-SILC and the rich information it has made available over the years.

The ACPI's mandate consists of carrying out studies and analyses about child poverty dynamics in Spain, designing and proposing measures to prevent and fight against child poverty to other ministries and bodies from both the administration and civil society, and the follow up and evaluation of actions, programs and policies in this field.

Since its creation, EU-SILC has been a crucial instrument for the realization of the ACPI's mission. Among other things, EU-SILC and, in particular, its Spanish version (Spanish Survey of Living Conditions (ES-SILC) allows, for instance, to estimate the extension and intensity of child poverty in Spain by using different poverty thresholds, to study its distribution by household composition, to explore the multidimensional nature of child poverty, and investigate the main characteristics of households with children in poverty and their poverty dynamics.

In this article, we will summarize some of the most relevant applications of the EU-SILC and ES-SILC done in the context of the ACPI's activities. In the process of analyzing SILC data, we have come across different limitations in the content, format and dissemination of the data. At the same time, comparing SILC with other potentially alternative and complementary data sources, we have confirmed many of its multiple strengths and advantages for a better understanding of poverty dynamics. We will describe some of these findings and their implications for public policy, and provide some proposals for improving the amount and quality of information to fight against child poverty through ES-SILC.

\section{Reforming child benefits to reduce child poverty}

One of the most relevant applications of EU-SILC when proposing policies aimed at reducing child poverty in Spain consisted in using its data to estimate the cost and impact of extending and increasing child benefits considering different potential scenarios. As the EU-SILC data illustrate, the current system of child allowances in Spain remains extremely inefficient in reducing child poverty, in comparison to other EU countries. Accordingly, ACPI explored the pace at which child benefits need to increase in order to eradicate extreme ( $25 \%$ of the median income) and high ( $40 \%$ of the median income) child poverty, and how to modulate coverage and generosity to make the cost of the reform tolerable for the State in the context of fiscal consolidation.

In Spain, we lack accurate information on individual and household income. Until very recently, tax information was never publicly exploited for this goal and, in any case, microdata from tax registers are not available. Moreover, income information based on tax registers entails certain limitations that particularly affect low-income households, especially when informal economy is important. For all these reasons, EU-SILC remains a crucial instrument when estimating poverty rates, even if its sample size may represent a limitation when examining extreme poverty for relatively small groups such as the child population.

Using EU-SILC information, ACPI estimated the size of child population in Spain living below different poverty lines $(60 \%, 40 \%$ and $25 \%$ of the median income) and proposed a gradual increase of child benefits over a period of four years, aimed at eradicating both extreme and high child poverty 


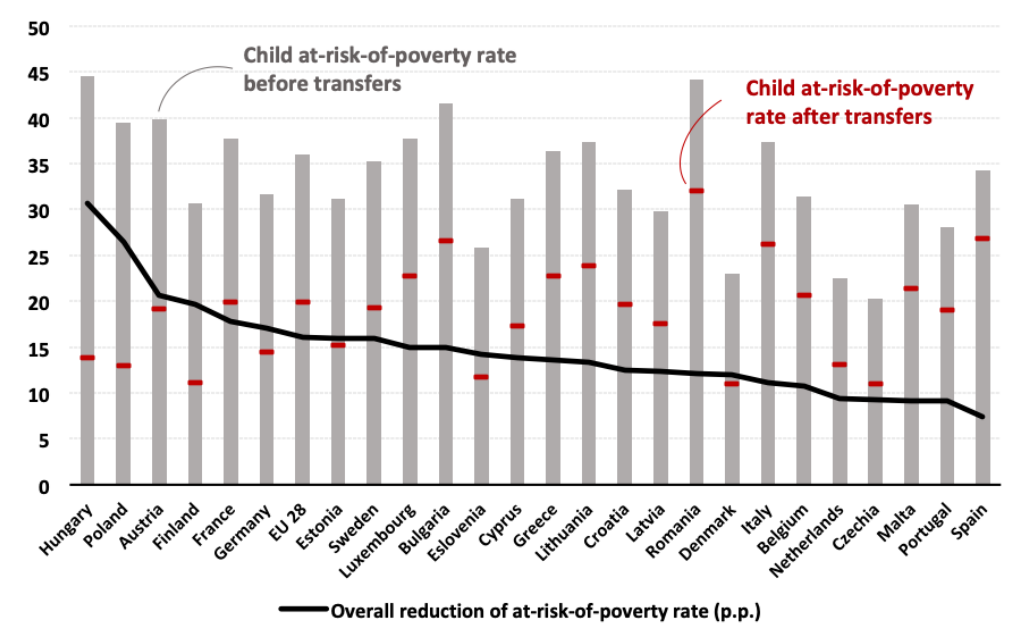

Figure 1: Child at-risk-of-poverty rate and its reduction by transfers EU-28 (2018). Source: Own compilation based on data from EU-SILC (2018).

by the end of the period. Table 1 summarizes the reduction achieved in extreme, high and moderate child poverty in the different years and scenarios considered for the estimations. During the first three years, the planned measures include only successive increases of the child benefits. In the fourth year, a Minimum Living Income for low-income families (regardless of the presence of children) would be deployed. Three different scenarios, in which both the beneficiaries and the amount provided to them vary, were considered. In Scenario 1, all households with annual income below a certain amount will receive a fixed benefit. In Scenarios 2 and 3, beneficiaries will be households with annual income below the $25 \%$ and $40 \%$ of the median income, respectively, and the amount they will receive should be enough to overcome those income thresholds. The administrative procedure to make the payment also varies across the scenarios.

\begin{tabular}{lccccccc}
\hline \hline \multicolumn{2}{l}{ Child poverty rate in 2017: } & Year 1 & Year 2 & Year 3 & Year 4(1) & Year 4 (2) & Year 4 (3) \\
\hline \hline Moderate (60\%) & $26.8 \%$ & $0 \%$ & $0 \%$ & $9 \%$ & $9 \%$ & $9 \%$ & $9 \%$ \\
High (40\%) & $12.4 \%$ & $8.1 \%$ & $23.4 \%$ & $23.4 \%$ & $26.6 \%$ & $23.4 \%$ & $100 \%$ \\
Extreme (25\%) & $5.2 \%$ & $21.2 \%$ & $46.2 \%$ & $46.2 \%$ & $75 \%$ & $100 \%$ & $100 \%$ \\
\hline \hline
\end{tabular}

Table 1: Child poverty rate reduction (in percentage). Source: Own compilation.

These estimations were the basis of the proposal to double the amount received by children in households below the 25\% median income threshold, finally approved in March 2019 by a Royal Decree. ${ }^{2}$ People below the $25 \%$ threshold largely overlap with people suffering material deprivation, a complementary indicator that informs us about the type of services and goods people cannot access because of economic difficulties.

As Table 2 shows, in any of the three scenarios considered in the original estimations, the proposed increase in the child allowance would benefit between 60 and 70 per cent of children living in households that declared to suffer difficulties to meet needs by the end of the month, go on va-

\footnotetext{
${ }^{2}$ We also replicated these estimations for year 1 with non-public information from the tax office to double check the results obtained using ES-SILC.
} 
cation once a year, and lack capacity to face unforeseen expenditures, respectively. In other words, setting the threshold at $25 \%$ of income poverty to define the beneficiaries of the child benefits increase ensured that the proposed reform focused on extreme child poverty.

However, when analyzing how income poverty overlaps with material deprivation some limitations arise. There are some material deprivation indicators that are clearly outdated, for instance "access to TV, phone and washing machine". In Spain, only 1 per cent of the total population declared impossibility to access these goods, even if they are considered to be in a situation of extreme poverty using any of the other indicators that compose the "material deprivation" measure. Therefore, its discriminatory power in identifying people in extreme poverty is very low. In any case, old indicators should be kept to preserve consistency over time. Nevertheless, future rounds of the survey should include new indicators in order to better capture child poverty, intergenerational transmission of poverty, and community and subjective dimensions of poverty.

\begin{tabular}{llll}
\hline \hline & IMV & Scenario 1 & Scenario 2 \\
\hline \hline a. Difficult or very difficult to make ends meet & $57.8 \%$ & $59.6 \%$ & $58.8 \%$ \\
b. Severe material deprivation (cannot afford at least four of the & $25,0 \%$ & $25.5 \%$ & $24.4 \%$ \\
following items) & & & \\
Go on holiday one week a year & $69.3 \%$ & $69.8 \%$ & $68.9 \%$ \\
Eat meat or proteins regularly & $12.5 \%$ & $13.6 \%$ & $15.1 \%$ \\
Keep their home adequately warm & $25.6 \%$ & $25.2 \%$ & $26 \%$ \\
Face unexpected expenses & $69.1 \%$ & $71.6 \%$ & $70 \%$ \\
Pay their rent, mortgage or utility bills & $25.2 \%$ & $30.9 \%$ & $26.3 \%$ \\
A car & $22.2 \%$ & $22.2 \%$ & $20.4 \%$ \\
\hline \hline
\end{tabular}

Table 2: Percentage of beneficiary households by type of severe material deprivation. The 2020 indicator also includes access to a television, telephone, and washing machine, but deprivation on these items is residual (about $1 \%$ ). Source: Own compilation.

\section{Evaluation of the program against energy poverty from a child perspec- tive}

The Ministry for Ecological Transition requested the ACPI's support to evaluate potential future reforms of the energy poverty benefits to evaluate, in particular, the coverage of different types of poor households guaranteed by the latest reform passed in October 2018. The analyses concluded that coverage was weaker for poor households composed by two adults with two children and households with more than two adults and at least one child, compared to all the remaining households including single parent families, large families or households composed only by low-pension retirees.

Without the precise information provided by the evaluation using ES-SILC data, typical households are unlikely to be considered as insufficiently covered and, therefore, adequately protected and supported. However, in the evaluation process, several limitations of ES-SILC became evident. The information contained in the survey does not allow to identify several of the special categories of beneficiaries defined in the "Bono Social" regulation such as people with disability equal or higher than 33\%, people with specific support needs for basic daily-life activities, low-income retirees, and victims of terrorism and gender violence. Their identification was only possible by linking individuals included in the ES-SILC to specific administrative registers, and this kind of operations are not always easy or possible. Alternatively, some questions could be added to the ES-SILC questionnaire 
allowing the interviewees to identify themselves, or not, as belonging to some of these groups of vulnerable people, with an explicit mention about the administrative recognition of their vulnerable condition when applicable.

In relation to this topic of energy poverty, the information collected by ES-SILC questionnaire in its current version remains too limited, especially if one takes into account the increasing relevance of this problem in a country like Spain. The indicator should be referred not only to adequate temperature during winter but also during summer, due to the strong impact that increasingly hot summers are having on particular regions and groups of people whose dwellings are not well prepared for such adverse climate conditions. In addition, also the cost of the service, even if approximate, is a crucial piece of information on this regard in order to facilitate the identification of hidden poverty. More generally, a rotating module on energy poverty could also be designed and implemented.

\section{Child poverty dynamics in immigrant and non-immigrant}

ACPI also carried out a comparison of child poverty dynamics among immigrant and non-immigrant households. Instead of focusing only on foreign versus national children, we linked child and household information to identify children living in immigrant and non-immigrant households according to their parents' place of birth. Both the foreign and the immigrant origin population are more likely to suffer higher poverty rates than the rest of the population in Spain due to several reasons, among which their occupational segregation and higher unemployment rates play a crucial role. The extent to which this situation translates into child poverty had not been carefully examined. Two important factors expected to affect child poverty by origin of the parents are eligibility and generosity of social benefits, and the age composition of the child population among immigrant and non-immigrant households, since we know that the cost varies depending on the age of the child.

The analysis of ES-SILC data, as summarized in Table 3, showed not only higher poverty rates among children but also, and most importantly, different patterns in the incidence of child poverty depending on the age of the child and their immigrant or non-immigrant origin. Poverty among children in immigrant households was approximately 3 times higher than among non-immigrant ones, before and after the crisis. However, in comparison to their non-immigrant counterparts, the poverty rate worsened much more among immigrant origin children below 4 years old (from 3.2 to 4.5 times higher), while it substantially reduced among adolescents.

\begin{tabular}{lcccccc}
\hline \hline & \multicolumn{2}{c}{$\mathbf{2 0 0 8}$} & \multicolumn{2}{c}{$\mathbf{2 0 1 7}$} & $\mathbf{2 0 0 8}$ & $\mathbf{2 0 1 7}$ \\
\hline & $\begin{array}{c}\text { Native } \\
\text { origin }\end{array}$ & $\begin{array}{c}\text { Immigrant } \\
\text { origin }\end{array}$ & $\begin{array}{c}\text { Native } \\
\text { origin }\end{array}$ & $\begin{array}{c}\text { Immigrant } \\
\text { origin }\end{array}$ & $\begin{array}{c}\text { Ratio (native } \\
\text { vs. Immigrant) }\end{array}$ & $\begin{array}{c}\text { Ratio (native } \\
\text { vs. Immigrant) }\end{array}$ \\
\hline Total & $19.8 \%$ & $57.1 \%$ & $22 \%$ & $65.4 \%$ & 2.9 & 3 \\
$<4$ years & $17.3 \%$ & $54.7 \%$ & $16.5 \%$ & $73.6 \%$ & 3.2 & 4.5 \\
$4-14$ years & $20.8 \%$ & $56.2 \%$ & $22.2 \%$ & $64.8 \%$ & 2.7 & 2.9 \\
15 - 17 years & $19.9 \%$ & $63.7 \%$ & $28.5 \%$ & $53.9 \%$ & 3.2 & 1.9 \\
\hline \hline
\end{tabular}

Table 3: Child poverty rate reduction (in percentage). Source: Own compilation.

The identification of these different dynamics among immigrant and non-immigrant origin households was possible thanks to the possibility of linking parents and children in ES-SILC, as well as the inclusion of information on age of the children year by year, and the origin of the parents. However, lacking of information on the actual country of birth beyond the basic distinction EU and non-EU prevents from a more detailed understanding of potential internal differences within the immigrant population. Moreover, the Spanish version of EU-SILC does not provide information 
either on whether children living in the surveyed households were born in Spain or abroad, nor their nationality. The omission of these two pieces of information seriously limits the possibility to better depict child poverty dynamics among immigrant origin children and, therefore, the convenience of designing specific policies to fight against it, or not, depending on the results. Finally, the major limitation of ES-SILC information when exploring poverty dynamics for immigrant populations, children or adults, has to do with the lack of information on their length of residence in the country. Length of residence in the country of immigration is the most critical variable in explaining different integration trajectories among immigrants, and its omission largely prevents a proper understanding of changes in living conditions of foreign-born people. For this reason, length of residence should be systematically asked in the survey for all the foreign-born members of the household.

By including information on place of birth for people below 16, and detailed information on years since arrival for all the foreign-born, ES-SILC would be a much better instrument to understand child poverty dynamics in immigrant households. In particular, the inclusion of these two pieces of information would allow to identify the role played by the recent arrival of their parents in Spain, the tougher impact of the crisis on immigrant households, and the different timing of entry into the labour market among immigrant origin adolescents compared to the non-immigrant ones to explain the observed patterns.

Here it is important to emphasize that the limited information collected by the survey in relation to the interviewees' retrospective labour trajectories greatly hampers a better understanding of the role played by this factor in shaping some of the reported differences. In its current version, the questionnaire collects monthly information about some dimensions of labour status but only for the previous year, which remains clearly insufficient to understand phenomena such as the increasing proportion of working poor or the very high rate or persistent poverty in Spain.

One additional issue related to the limitation in ES-SILC to study poverty dynamics in immigrant origin households has to do with the deficient design of the variable HX060 "Type of household". First of all, the category "others" is a black box particularly frequent for specific groups such as immigrant origin households in vulnerable situations. A better understanding of the composition of their households seems convenient. Secondly, regardless of the immigrant origin of the household, this variable classifies as dependent children individuals from 18 to 25 if they are not active in the labour market. Finally, from a user-friendly perspective, it would be desirable to add a different variable that considers categories that specifies single parent, cohabitating parental couple, etc., and always considering the number of children in the household.

Finally, in future versions of the survey, it would be ideal to provide information that allows to identify different family units within the households, an important issue taking into account that multi-family households are much more common among vulnerable groups compared to the average household.

\section{Impact of housing prices on child poverty}

ACPI also conducted a comparative analysis of the components and dynamics of child poverty in Spain focusing on the role played by the housing market before, during and after the crisis, using ESSILC data. First, the results clearly showed how the "housing cost overburden rate" (when the cost of housing represents more than 40 per cent of household total disposable income) is systematically associated with poverty in Spain. Approximately, 40 per cent of the poor suffer overburden rate, and this percentage has hardly varied over the period 2007-2017. Second, child population, again, suffers a higher overburden rate than the adult population, regardless of poverty. In addition, overburden 
is much more frequent for child population in Spain than in the rest of Europe, especially if they are poor children. Moreover, more importantly, in Spain the housing cost overburden rate is larger among the child population in poverty than among the total population in poverty, while the opposite pattern is observed in the EU, on average. This situation highlights the weak housing policies and their major contribution to poverty in general, and child poverty in particular, in our country.

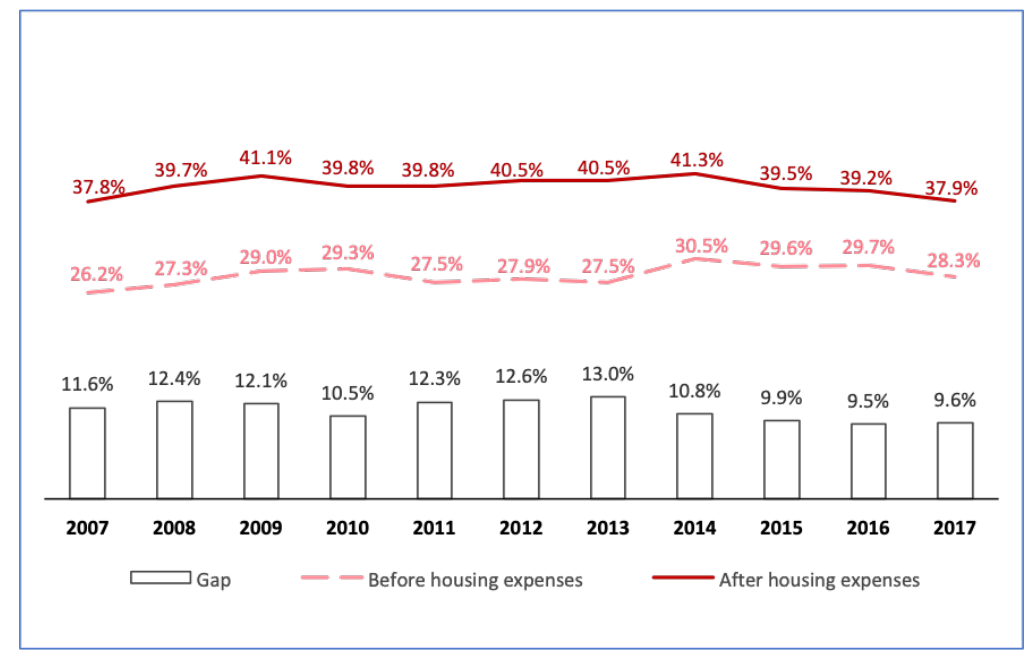

Figure 2: Child at-risk-of-poverty-rate before and after housing expenses in Spain (2007-2017). Source: EU-SILC (2007-2017).

When analyzing these data, it became evident the lack of some relevant information on the dwelling characteristics, as well as regarding the process of housing acquisition and/or renting. Given the high proportion housing expenditures represent over the total household income in Spain, and their major contribution to income poverty, additional information on the registered value of the dwelling, the pending mortgage, and the existence of other real estate properties beyond the usual dwelling, are relevant for a better understanding of the living conditions of the household members and their financial constraints.

\section{Module on childcare}

Finally, another area with room for improvement to contribute to a better understanding of child poverty and, more generally, inequality in children's living conditions has to do with the battery of questions about childcare included in the EU-SILC questionnaire. The module collects information on the weekly number of hours of different types of care provided to children under 12 in the household (parental care, schooling, early childhood education and care (0-3 years), at-home professional care or grandparental care). Unfortunately, this information is of very limited use in understanding increasing patterns of inequality among children if complementary information on aspects such as the cost of these services, the public or private nature of the child care centre, the distance from the dwelling to the (closest) child care centre, or the reasons why these services are not used, are fully omitted in the survey. This complementary information is crucial in order to identify obstacles and inequality in accessing public education services, for instance, and reasons underlying the decision to take children to childcare and early education, which is known to be crucial (conditional on quality) for the future development and opportunities of the children. 
In relation to this topic, better information on school expenditures, with special attention to school meal services and nutrition remains an urgent need for both policy makers and researchers.

\section{Other limitations and potential improvements}

In this article, we have revised some of the applications that the High Commissioner against Child Poverty made over 2018/2019 using the valuable information contained in EU-SILC and, in particular, ES-SILC for the analysis of multiple dimensions of child poverty in Spain. EU-SILC has become a central instrument for exploring crucial social problems in our societies, with the enormous advantage of its highly standardized quality, periodicity and international comparability. As this article has briefly summarized, its potentialities for better understanding of child poverty and its multidimensional nature are multiple. However, there is room for improvement in relation to areas such as housing, childcare, school expenditures and labour market trajectories, which are strongly linked to poverty dynamics in general, and child poverty in particular. 